\title{
Structural and thermal characterization of galactomannans from non-conventional sources
}

\author{
Miguel A. Cerqueira ${ }^{a}$, Bartolomeu W.S. Souza ${ }^{a}$, Joana Simões ${ }^{b}$, José A. Teixeira ${ }^{a}$, \\ M. Rosário M. Domingues ${ }^{b}$, Manuel A. Coimbra ${ }^{b}$, António A. Vicente ${ }^{\mathrm{a}, *}$ \\ a IBB - Institute for Biotechonolgy and Bioengineering, Centre of Biological Engineering, Universidade do Minho, Campus de Gualtar, 4710-057 Braga, Portugal \\ ${ }^{\mathrm{b}}$ QOPNA - Departamento de Química, Universidade de Aveiro, 3810-193 Aveiro, Portugal
}

\section{A R T I C L E I N F O}

\section{Article history:}

Received 17 June 2010

Received in revised form 15 July 2010

Accepted 19 July 2010

Available online 23 July 2010

\section{Keywords:}

Galactomannan

Methylation

Electrospray Mass Spectrometry

TGA

DSC

FTIR

\begin{abstract}
A B S T R A C T
Galactomannans of Gleditsia triacanthos, Caesalpinia pulcherrima and Adenanthera pavonina were structurally and thermally characterized. Methylation analyses confirmed that these three galactomannans are composed by a 4-linked mannose polymer with galactose side chains attached at the C6 position. $G$. triacanthos galactomannan had an estimated average degree of polymerization of 224 mannose residues, with a degree of branching of $0.24, C$. pulcherrima galactomannan had a degree of polymerization of 252 and a degree of branching of 0.30 , and A. pavonina galactomannan had a degree of polymerization of 475 and a degree of branching of 0.60 . Enzymatic hydrolysis with endo- $\beta$-mannanase and the subsequent analyses of the low molecular weight fraction by ESI-MS/MS indicated the presence of characteristic structural features of galactomannans. Furthermore, acetyl and pentosyl residues were detected in the galactomannan of $G$. triacanthos and analyses of higher molecular weight fractions from $G$. triacanthos were performed, confirming that presence. Differential scanning calorimetry (DSC) showed the presence of two peaks related with water loss, confirmed by thermogravimetric analysis (TGA). The different compositions of galactomannans with different mannose content and different molecular weights influence their thermal behaviour. A higher content of mannose lead to higher values of the enthalpy change (first thermal transition) and glass transition temperature $\left(T_{g}\right)$, while the enthalpy change of the second thermal transition was influenced by the viscosity average molecular weight $(M v)$ of the samples.

This work provides understanding of structural and thermal properties of three galactomannans from non-conventional sources, thus contributing to a better insight on their possible food, pharmaceutical or biomedical applications.
\end{abstract}

(C) 2010 Elsevier Ltd. All rights reserved.

\section{Introduction}

In general, hydrocolloids are hydrophilic molecules with high molecular weight that can be used by food industry to modify texture, rheological characteristics, appearance and conservation of food stuffs due to their ability to stabilize emulsions and dispersions and retain water (Rosell, Rojas, \& De Barber, 2001). Currently, consumers' demand for healthier, safer and novel natural foods fostered the introduction of alternative sources of seed gums (Joshi \& Kapoor, 2003) and it is therefore important to characterize such materials in view of their possible applications. Biodegradable polymers are interesting for biomedical engineering, featuring two major advantages over non-biodegradable polymers: they are gradually absorbed by the human body, and some of them are able to regenerate tissues through the interaction of their biodegrada-

\footnotetext{
* Corresponding author. Tel.: +351253 604419; fax: +351253678986.

E-mail address: avicente@deb.uminho.pt (A.A. Vicente).
}

tion with immunologic cells (Chu, 2003). They may also be used, e.g. for the production of edible and biodegradable films and coating materials (Cerqueira, Lima et al., 2009).

Galactomannans, extracted from the endosperm of numerous plants (particularly the Leguminosae) are polysaccharides built up of a $\beta$-(1-4)-D-mannan backbone with single D-galactose branches linked $\alpha-(1-6)$. They are water soluble hydrocolloids forming highly viscous, stable aqueous solutions (Neukom, 1989). Galactomannans can often be used in different forms for human consumption. Featuring different physicochemical properties, galactomannans are a versatile material used for many applications: they are excellent stiffeners and stabilizers of emulsions, and the absence of toxicity allows their use in the textile, pharmaceutical, biomedical, cosmetics and food industries (Srivastava \& Kapoor, 2005; Vieira, Mendes, Gallão, \& de Brito, 2007; Yi \& Zhang, 2007).

Commercially available galactomannans such as locust bean gum (Ceratonia siliqua), guar gum (Cyamopsis tetragonolobus) and tara gum (Caesalpinea spinosa) have found applicability as controlled release agents (Baveja, Ranga Rao, Arora, Mathur, \& Vinayah, 
1991; Krishnaiah, Karthikeyan, Gouri Sankar, \& Satyanarayana, 2002; Varshosaz, Tavakoli, \& Eram, 2006). In order to guarantee the application of galactomannans in pharmaceutical and biomedical industries a full characterization is necessary (Vendruscolo et al., 2009). In particular, Latin American sources of galactomannans are not well known, in spite of the rich biodiversity of the local flora and of the favourable climate for their production (Azero \& Andrade, 2002).

Non-traditional galactomannans were isolated from seeds of Gleditsia triacanthos, Caesalpinia pulcherrima and Adenanthera pavonina. Their yield of extraction, monosaccharide composition, mannose/galactose ratio, intrinsic viscosity and viscosity average molecular weight were previously reported (Cerqueira, Pinheiro et al., 2009). In the present work they were further characterized by methylation analysis and by enzymatic hydrolysis followed by analysis by tandem mass spectrometry (MS/MS) using electrospray ionization (ESI). Their thermal characterization was performed by thermogravimetric analysis (TGA) and differential scanning calorimetry (DSC) together with a characterization by Fourier transform infrared (FTIR) spectroscopy.

\section{Materials and methods}

\subsection{Raw material}

Galactomannans from G. triacanthos (GT), C. pulcherrima (CP) and $A$. pavonina (AP) were obtained as previously described in Cerqueira, Pinheiro et al. (2009).

\subsection{Methylation and GC/MS analyses}

Polysaccharides were activated with powdered $\mathrm{NaOH}$ and methylated with $\mathrm{CH}_{3}$ I (Ciucanu \& Kerek, 1984; Isogai, Ishizu, \& Nakano, 1985) as described by Coimbra et al. (1996). The sample (2-3 mg) was dispersed in $2 \mathrm{~mL}$ of dried DMSO and sonicated occasionally until it was fully dispersed. $\mathrm{NaOH}$ pellets $(100 \mathrm{mg}$ ) powdered under argon were added to the solution. The sample was sonicated for $90 \mathrm{~min}$ and allowed to stand for an additional $90 \mathrm{~min}$. The methylated material was dissolved in $3 \mathrm{~mL}$ of water and extracted with $4 \mathrm{~mL}$ of chloroform. The organic layer was washed three times with $3 \mathrm{~mL}$ of water, evaporated to dryness, and remethylated to achieve a complete methylation of all free $\mathrm{OH}$ groups. The fully methylated material was then hydrolyzed with $2 \mathrm{M}$ trifluoroacetic acid $(1 \mathrm{~mL})$ at $121^{\circ} \mathrm{C}$ for $1 \mathrm{~h}$, cooled, and rotary evaporated at $35^{\circ} \mathrm{C}$. The partially methylated sugars were then dissolved in $0.3 \mathrm{~mL}$ of $2 \mathrm{M} \mathrm{NH}_{3}$ and $20 \mathrm{mg}$ of $\mathrm{NaBD}_{4}$ were added. The mixture was allowed to react at $30^{\circ} \mathrm{C}$ for $1 \mathrm{~h}$, and the excess of the reducing agent was destroyed by the addition of $0.1 \mathrm{~mL}$ of glacial acetic acid. The acetylation of the partially methylated alditols was performed by adding 1 -methylimidazole $(0.45 \mathrm{~mL})$ and acetic anhydride $(3 \mathrm{~mL})$ and allowing to react for $30 \mathrm{~min}$ at $30^{\circ} \mathrm{C}$. This solution was treated with water $(3 \mathrm{~mL})$ to decompose the excess of acetic anhydride, and the partially methylated alditol acetates (PMAA) were extracted with dichloromethane (3-5 mL). The dichloromethane phase was washed with water and evaporated to dryness. The PMAA were dissolved in dichloromethane $(70 \mu \mathrm{L})$ and analyzed by GC-MS. GC-MS analysis was performed in a HP series 2 gas chromatograph and Trio-1S VG mass-lab using a DB- 1 capillary column ( $30 \mathrm{~m}$ length, $0.32 \mathrm{~mm}$ i.d., and $0.25 \mu \mathrm{m}$ of film thickness). The samples were injected in splitless mode (time of splitless $0.75 \mathrm{~min}$ ), with the injector and detector operating at 210 and $220^{\circ} \mathrm{C}$, respectively, using the following temperature program: $55^{\circ} \mathrm{C}$ for $0.75 \mathrm{~min}$ followed by a linear increase of $45^{\circ} \mathrm{C} \mathrm{min}{ }^{-1}$ until $140^{\circ} \mathrm{C}$, and standing $1 \mathrm{~min}$ at this temperature, followed by a linear increase of $2.5^{\circ} \mathrm{C} \mathrm{min}^{-1}$ until $218^{\circ} \mathrm{C}$, with further $37 \mathrm{~min}$ at $218^{\circ} \mathrm{C}$. Linear velocity of the carrier gas (He) was set at $40 \mathrm{~cm} \mathrm{~s}^{-1}$ at $200^{\circ} \mathrm{C}$, with a solvent delay of $4 \mathrm{~min}$. MS scans were performed for GC-MS between 400 and $35 \mathrm{~m} / \mathrm{z}$ at $70 \mathrm{eV}$ ionization energy.

\subsection{Enzymatic hydrolysis}

Samples (14 mg) were hydrolyzed with pure endo- $\beta$-(1-4)mannanase ( $1 \mathrm{U}$ ) preparation (Megazyme, EC 3.2.1.78) during $48 \mathrm{~h}$ at $37^{\circ} \mathrm{C}$ with continuous stirring in a $100 \mathrm{mM}$ Na-acetate buffer $\mathrm{pH} 5.5$ containing $0.02 \%$ sodium azide. The freeze-dried material was dissolved in pyridine-acetate $100 \mathrm{mM}$ buffer $\mathrm{pH} 5.25$, and loaded on a XK 1.6/100 column containing Biogel P-4 (BioRad) previously equilibrated with the same buffer. Fractions ( $1 \mathrm{~mL}$ ) were collected and assayed for sugars by static light scattering (Sedere, France). Results were subsequently confirmed by the phenol- $\mathrm{H}_{2} \mathrm{SO}_{4}$ method (Dubois, Gilles, Hamilton, Rebers, \& Smith, 1956). The appropriate fractions were pooled and rotary evaporated until all buffer was removed by repeated additions of distilled water, and freeze-dried.

\subsection{Electrospray ionization mass spectrometry (ESI-MS and ESI-MS/MS)}

Freeze-dried fractions obtained after enzymatic hydrolysis and fractionated through Biogel P4 column were dissolved in $200 \mu \mathrm{L}$ of $1: 1 \mathrm{MeOH}$-water containing $1 \%(\mathrm{v} / \mathrm{v})$ formic acid. Samples were introduced into the mass spectrometer using a flow rate of $8 \mu \mathrm{L} \mathrm{min}^{-1}$. Positive-ion ESI-MS and MS/MS spectra were acquired using a LXQ linear ion trap mass spectrometer (ThermoFinnigan, San Jose, CA). Typical ESI conditions were: nitrogen sheath gas 30 psi, spray voltage $5 \mathrm{kV}$, heated capillary temperature $275^{\circ} \mathrm{C}$, capillary voltage $1 \mathrm{~V}$ and tube lens voltage $40 \mathrm{~V}$. The precursor ion accumulation time for each scan was controlled by the automatic gain control function of the instrument. ESI-MS/MS experiments were performed on mass-selected precursor ions using standard isolation and excitation procedures (activation q value of 0.25 , activation time of $30 \mathrm{~ms}$ ). The collision energy used was between 20 and 24 (arbitrary units). Data acquisition was carried out with an Xcalibur data system.

\subsection{Thermogravimetric analysis (TGA) and differential scanning calorimetry (DSC)}

TGA and DSC measurements were carried out in $\mathrm{N}_{2}$ atmosphere using a Shimadzu TGA-50 and a Shimadzu DSC-50 equipment (Shimadzu Corporation, Kyoto, Japan) calibrated with Indium as standard. Analyses were started at $20^{\circ} \mathrm{C}$ and continued up to $580^{\circ} \mathrm{C}$, with a linear increase of $10^{\circ} \mathrm{C} \mathrm{min}^{-1}$. Samples were weighed (approximately 5-10 mg of dry matter) in Aluminium DSC pans (Al crimp Pan C.201-52943) being the empty pans used as a reference. Data were treated using TASYS software (Shimadzu Corporation, Kyoto, Japan). Enthalpy was calculated using the area of the peaks between the onset temperature and the end set temperature. For glass transition temperature $\left(T_{g}\right)$ determinations two heating runs were performed between 20 and $250^{\circ} \mathrm{C}$. After the first heating run the samples were left to cool naturally at room temperature under $\mathrm{N}_{2}$ atmosphere. The second run was used for $T_{g}$ determination (Dong, Ruan, Wang, Zhao, \& Bi, 2004; Mitsuiki, Yamamoto, Mizuno, \& Matoki, 1998; Yi \& Zhang, 2007).

\subsection{Fourier transform infrared (FTIR) spectroscopy}

IR spectra of the polysaccharides were determined using a Fourier transform infrared spectrometer(FTIR)(Perkin-Elmer 16 PC spectrometer, Boston, USA). The polysaccharide was ground with spectroscopic grade potassium bromide $(\mathrm{KBr})$ powder and then 
Table 1

Glycosidic-linkage analyses of G. triacanthos (GT), C. pulcherrima (CP) and A. pavonina (AP) galactomannans.

\begin{tabular}{|c|c|c|c|}
\hline \multirow[t]{2}{*}{ Linkage } & \multicolumn{3}{|c|}{ Relative abundance (\%) } \\
\hline & GT & $\mathrm{CP}$ & $\mathrm{AP}$ \\
\hline Terminal-Man $p$ & $0.35 \pm 0.17$ & $0.30 \pm 0.09$ & $0.13 \pm 0.11$ \\
\hline 4-Manp & $59.15 \pm 4.57$ & $53.18 \pm 7.16$ & $24.73 \pm 0.48$ \\
\hline 4,6-Manp & $18.93 \pm 4.51$ & $22.05 \pm 3.81$ & $36.84 \pm 9.48$ \\
\hline Total Man & $78.43 \pm 4.07(66.9)^{a}$ & $75.53 \pm 2.86(69.1)^{\mathrm{a}}$ & $61.70 \pm 9.19(52.8)^{\mathrm{a}}$ \\
\hline $\mathrm{DPm}$ & 224 & 252 & 475 \\
\hline Terminal-Galp & $17.23 \pm 4.50$ & $20.92 \pm 3.62$ & $34.02 \pm 7.80$ \\
\hline 4-Galp & $3.45 \pm 1.03$ & $2.70 \pm 0.05$ & $2.95 \pm 0.28$ \\
\hline Total Gal & $20.69 \pm 3.81(23.7)^{\mathrm{a}}$ & $26.21 \pm 3.68(24.0)^{a}$ & $36.97 \pm 7.52(39.2)^{\mathrm{a}}$ \\
\hline Terminal-Araf & $0.55 \pm 0.15$ & $0.24 \pm 0.22$ & - \\
\hline 5-Araf & $0.34 \pm 0.13$ & $0.51 \pm 0.35$ & $0.83 \pm 0.65$ \\
\hline Total Ara & $0.89 \pm 0.27(4.5)^{a}$ & $0.92 \pm 0.06(1.2)^{\mathrm{a}}$ & $0.52 \pm 0.34(0.8)^{a}$ \\
\hline
\end{tabular}

a Values of monosaccharide composition obtained in Cerqueira, Pinheiro et al. (2009).

pressed into $1 \mathrm{~mm}$ pellets for FTIR measurement in the wavenumber range of 400 and $4000 \mathrm{~cm}^{-1}$ using 16 scans. Each spectrum was baseline corrected and the absorbance was normalised between 0 and 1.

\section{Results and discussion}

\subsection{Methylation and GC-MS analyses}

Table 1 shows the glycosidic linkage composition of the three galactomannans. Partially methylated alditol acetates analyzed by GC/MS revealed a polysaccharide containing nonreducing terminal units of Manp (0.35\%, 0.30\% and 0.13\%) and Galp (17.23\%, 20.92\% and $34.02 \%$ ) as well as 4 -Manp (59.15\%, 53.18\% and 24.73\%), 4,6Manp (18.93\%, 22.05\% and 36.84\%) and 4-Galp (3.45\%, 2.70\% and $2.95 \%$ ), for $G$. triacanthos, C. pulcherrima and A. pavonina, respectively. The results of the methylation analyses confirm the structure of the galactomannans as a 1-4 mannose with galactose side chains attached at the $\mathrm{C} 6$ position. The total content of mannosyl and galactosyl residues is in agreement with previous work on monosaccharide composition (Cerqueira, Pinheiro et al., 2009). Results also show the presence of arabinose residues in galactomannan extracts as reported in other works with G. triacanthos (Manzi, Ancibor, \& Cerezo, 1990; Navarro, Cerezo, \& Stortz, 2002).

The degree of polymerization of mannose residues for the three galactomannans are within the range usually found for polysaccharides structures (above 100) (Izydorczyk, 2005), showing in this case the greater value for A. pavonina galactomannan. G. triacanthos galactomannan had an estimated average degree of polymerization of 224 mannose residues, with a degree of branching of $0.24, C$. pulcherrima had a degree of polymerization of 252 and a degree of branching of 0.30 , and $A$. pavonina had a degree of polymerization of 475 and a degree of branching of 0.60 . These values are in line with the values of the viscosity average molecular weight $(M v)$ reported by Cerqueira, Pinheiro et al. (2009), showing a positive correlation between the degree of polymerization and $M v$, although the values obtained by methylation analysis are much lower (40-80 kDa) than those obtained by viscosity measurements (1.6-1.8 MDa). These differences are possibly due to some polysaccharide depolymerization during methylation, as previously suggested by Nunes and Coimbra (2001).

\subsection{Enzymatic hydrolyses and ESI-MS analyses}

Galactomannan samples were submitted to endo- $\beta$-mannanase hydrolyses in order to determine their detailed molecular structure, followed by size-exclusion chromatography (SEC) on a Biogel-P4 column, in order to obtain size-homogeneous oligosaccharide fractions $\left(F_{1}-F_{3}\right)$. The results in the chromatograms corresponding to
G. triacanthos (GT), C. pulcherrima (CP) and A. pavonina (AP) samples are shown in Fig. 1a-c, respectively. According to the known enzymatic mechanism of Aspergillus niger endo- $\beta$-mannanase, the hydrolysis of $\beta$-(1-4)-linked mannan backbone is hindered by the presence of Gal residues, e.g. the extent of hydrolysis is higher for low galactose-substituted mannan backbones (Daas, Schols, \& Jongh, 2000). The elution profile obtained by SEC after endo- $\beta$ mannanase hydrolyses showed different abundances of $F_{3}, F_{2}$ and $F_{1}$ fractions in each sample. The GT sample showed the highest abundance of low molecular weight fractions, when compared with the other samples, while AP presented the lowest abundance of fractions with lower molecular weight. This pattern can be related with the values of the degree of branching for these polysaccharides. AP galactomannan presents the highest value of degree of

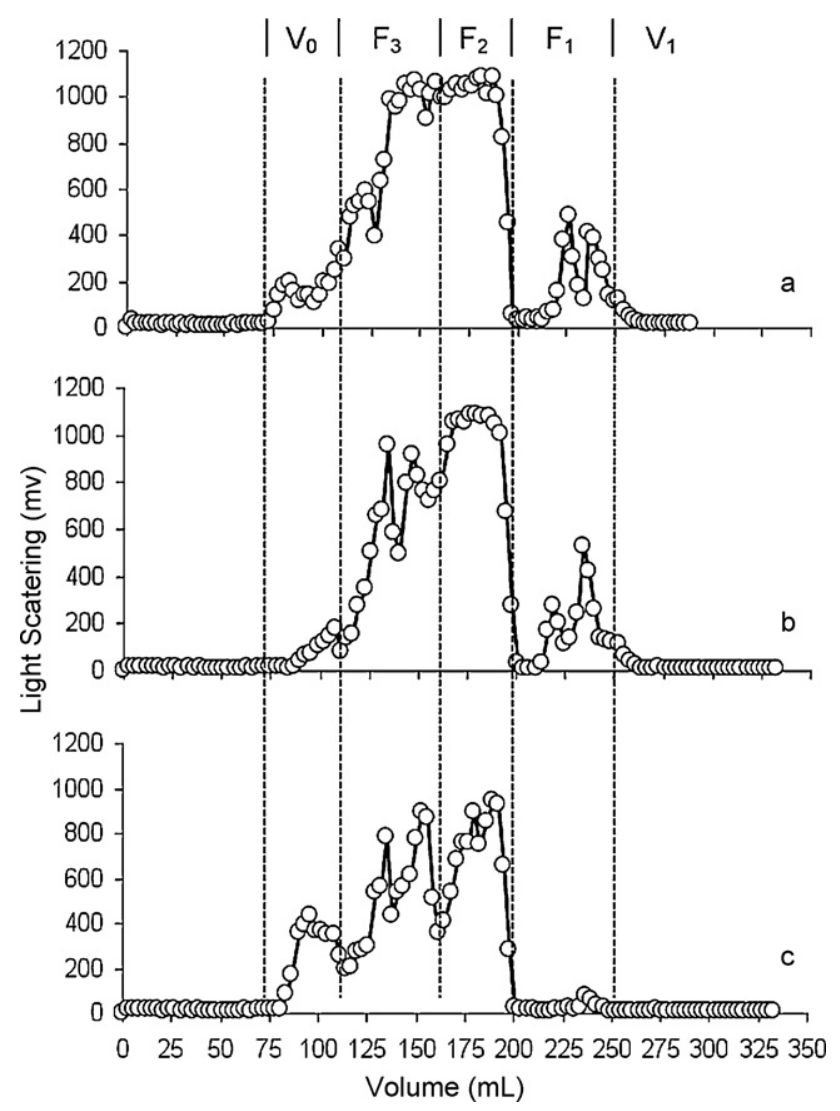

Fig. 1. Size-exclusion chromatography of oligosaccharides obtained after hydrolysis with endo- $\beta$-mannanase for (a) G. triacanthos, (b) C. pulcherrima and (c) A. pavonina. $V_{0}$ - void volume; $V_{1}$ - total volume. $\mathrm{F}_{1}-\mathrm{F}_{3}$ are oligosaccharide fractions with increasing molecular weights. 
Table 2

Oligosaccharide $m / z$ ions $\left([\mathrm{M}+\mathrm{Na}]^{+}\right)$observed by ESI-MS after hydrolysis with endo- $\beta$-mannanase of $G$. triacanthos (GT), C. pulcherrima (CP) and A. pavonina (AP) galactomannans.

\begin{tabular}{|c|c|c|c|c|c|c|}
\hline \multirow[t]{2}{*}{ Sample, $n$} & \multicolumn{6}{|l|}{ GT } \\
\hline & 2 & 3 & 4 & 5 & 6 & 7 \\
\hline$\left[\mathrm{Hex}_{n}+\mathrm{Na}\right]^{+}$ & 365 & 527 & 689 & 851 & 1013 & 1175 \\
\hline$\left[\mathrm{AcHex}_{n}+\mathrm{Na}\right]^{+}$ & & 569 & & 893 & 1055 & \\
\hline$\left[\mathrm{Hex}_{n} \mathrm{AcPent}+\mathrm{Na}\right]^{+}$ & & 701 & & & & \\
\hline \multirow[t]{2}{*}{ Sample, $n$} & \multicolumn{6}{|c|}{$\mathrm{CP}$} \\
\hline & \multicolumn{3}{|c|}{2} & \multicolumn{2}{|l|}{3} & 4 \\
\hline$\left[\mathrm{Hex}_{n}+\mathrm{Na}\right]^{+}$ & \multicolumn{3}{|c|}{365} & \multicolumn{2}{|l|}{527} & 689 \\
\hline \multirow[t]{2}{*}{ Sample, $n$} & \multicolumn{3}{|c|}{$\mathrm{AP}$} & & & \\
\hline & \multicolumn{3}{|c|}{2} & \multicolumn{2}{|l|}{3} & 4 \\
\hline$\left[\mathrm{Hex}_{n}+\mathrm{Na}\right]^{+}$ & \multicolumn{3}{|c|}{365} & 527 & & 689 \\
\hline
\end{tabular}

branching (lowest abundance of fractions with lower molecular weight) while the GT galactomannan presents the lowest value of degree of branching (higher abundance of fractions with lower molecular weight).

The analysis by ESI-MS allows studying intact oligosaccharides, even when present in mixtures and with low abundance, without any manipulation/derivatization being required (Nunes, Domingues, \& Coimbra, 2005). ESI-MS spectra of oligosaccharide $\mathrm{F}_{1}$ fractions obtained from GT, CP and AP polysaccharides present similar features. Table 2 shows the oligosaccharides identified as $[\mathrm{M}+\mathrm{Na}]^{+}$ions in ESI-MS spectra of galactomannans from GT, CP and AP. The major oligosaccharides of $F_{1}$ for each of the three studied galactomannans were identified as the sodium adducts $[\mathrm{M}+\mathrm{Na}]^{+}$of $\mathrm{Hex}_{2}$ and $\mathrm{Hex}_{3}$ followed by Hex 4 at $m / z$ 365, $m / z 527$ and $m / z$ 689, respectively. On GT samples the presence of ions at $m / z 569$ and $m / z$ 701, attributed to the acetylated tri- and tetrasaccharides $\mathrm{Hex}_{3} \mathrm{Ac}_{1}$ and $\mathrm{Hex}_{3} \mathrm{Ac}_{1}$ Pent $_{1}$, respectively, were detected. To confirm the presence of acetyl and pentosyl groups in GT polysaccharide, $F_{2}$ fraction was submitted to a second SEC in a Biogel-P4 column, leading to two fractions: $F_{21}$ and $F_{22}$ (Fig. 2). After this purification step, the acetylated groups were still detected, with the presence of ions at $m / z 893$ and 1055 , attributed to the acetylated pentaand hexasaccharides. In these $F_{21}$ and $F_{22}$ fractions, the sodium adducts $[\mathrm{M}+\mathrm{Na}]^{+}$of $\mathrm{Hex}_{5}, \mathrm{Hex}_{6}$ and $\mathrm{Hex}_{7}$ were detected at $\mathrm{m} / \mathrm{z}$ $851, m / z 1013$ and $m / z 1175$, respectively (Table 2 ). The presence of acetyl groups was observed in other works that used ESI-MS and MS/MS for the characterization of galactomannans (Nunes et al., 2005). In order to confirm the proposed oligosaccharide structures observed in the ESI-MS spectra, these ions were further analyzed by ESI-MS/MS.

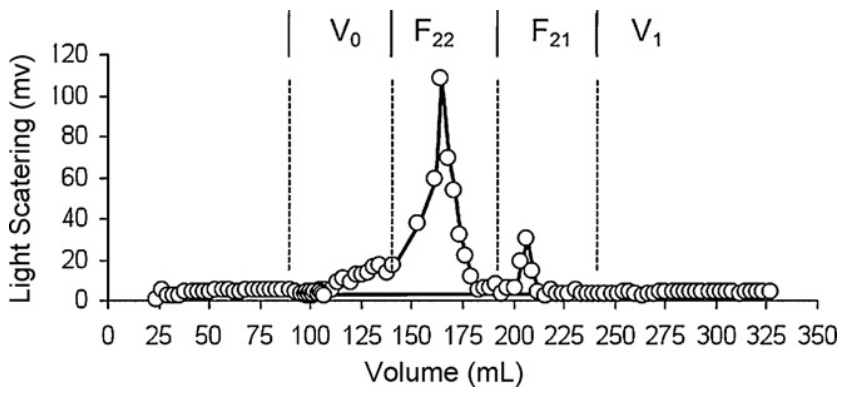

Fig. 2. Size-exclusion chromatography of fraction $F_{2}$ from $G$. triacanthos galactomannan. $V_{0}$ - void volume; $V_{1}$ - total volume. $F_{21}$ and $F_{22}$ are oligosaccharide fractions with increasing molecular weights.
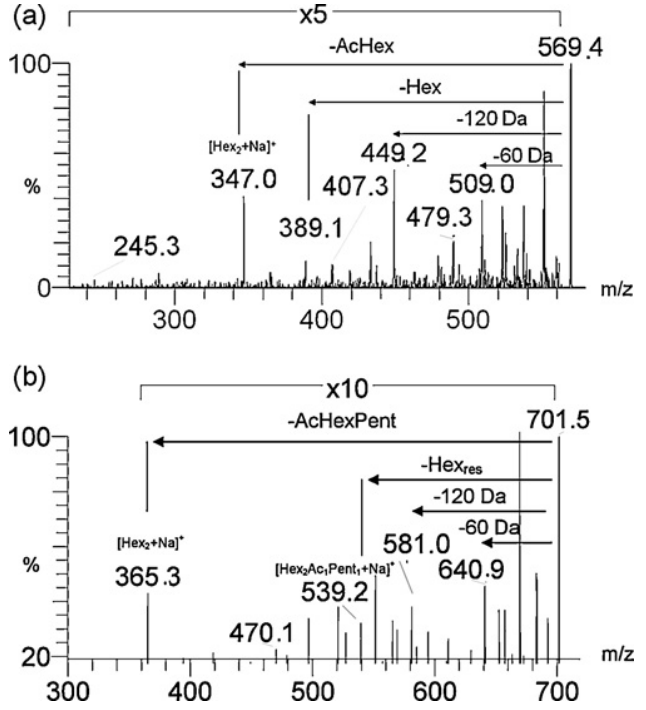

Fig. 3. ESI-MS/MS spectra of $[\mathrm{M}+\mathrm{Na}]^{+}$adducts and schematic fragmentation pathways of $\operatorname{Hex}_{3} \mathrm{Ac}_{1}$ (a) and $\mathrm{Hex}_{3} \mathrm{Ac}_{1}$ Pent $_{1}$ (b) for fraction $\mathrm{F}_{1}$ of $G$. triacanthos.

\subsection{ESI-MS/MS spectra of the obtained oligosaccharides}

Oligosaccharide cleavages under ESI-MS/MS conditions are the result of glycosidic cleavages between two sugar residues and of cross-ring cleavages (cleavage of two bonds within the sugar ring).

\subsubsection{G. triacanthos}

The ESI-MS/MS spectrum of $\left[\mathrm{Hex}_{2}+\mathrm{Na}\right]^{+}(\mathrm{m} / \mathrm{z} 365)$ and $\left[\mathrm{Hex}_{3}+\mathrm{Na}\right]^{+}(m / z 527)$ for GT (results not shown) present predominant ions attributed to a glycosidic cleavage. The higher intensity of the loss of a neutral fragment with $60 \mathrm{Da}$ is characteristic of a cross-ring ${ }^{0.2} \mathrm{~A}_{2}$ cleavages, related with the (1-4)-linked hexoses. Also the absence of product ions due to losses of $90 \mathrm{Da}$, are characteristic of the MS/MS spectrum of 4-linked hexoses (Hofmeister, Zhou, \& Leary, 1991).

The ESI-MS/MS spectrum of $\left[\mathrm{Hex}_{3} \mathrm{Ac}+\mathrm{Na}\right]^{+}(\mathrm{m} / z 569)$, presented in Fig. 3a, showed the presence of the ions at $m / z 389$ and $m / z$ 347, corresponding to the loss of a Hex unit ( $-180 \mathrm{Da})$ and of the loss

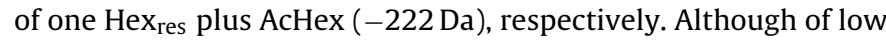
intensity, it is observed the ions at $\mathrm{m} / \mathrm{z} 407$ and $\mathrm{m} / \mathrm{z} 245$ due the loss of one and two Hex $\mathrm{res}_{\mathrm{r}}(162$ and $324 \mathrm{Da}$ ), respectively. Fig. 3a also shows the ions at $m / z 509$ (loss of $60 \mathrm{Da}), \mathrm{m} / z 479$ (loss of $90 \mathrm{Da}$ ) and, with higher abundance, the ion at $\mathrm{m} / z 449$ (loss of $120 \mathrm{Da}$ ), corresponding to a 1-6 type linkage (Nunes et al., 2005). These fragmentation pathways allowed to identify this oligosaccharide as being composed by two Man units linked by a (1-4) linkage and an additional Gal residue (1-6)-linked, in accordance with methylation analysis. Also, the loss of AcHex ( $-222 \mathrm{Da})$ confirm the presence of an acetylated hexose unit.

The ESI-MS/MS spectrum of $\left[\mathrm{Hex}_{3} \mathrm{AcPent}+\mathrm{Na}\right]^{+}(\mathrm{m} / \mathrm{z} 701)$ (Fig. $3 \mathrm{~b}$ ), show the product ions at $m / z 539$, corresponding to the loss of one Hex res ( $-162 \mathrm{Da})$, and at $m / z 365$, attributed to the loss of one block HexAcPent. To confirm the presence of acetyl groups on this galactomannan structure the oligosaccharides at $\mathrm{m} / \mathrm{z} 893$ and $m / z 1055$ observed in the fraction $\mathrm{F}_{22}$ were also analyzed by ESI-MS/MS (Fig. 4).

Fig. 4a shows the ESI-MS/MS spectrum of $\left[\mathrm{Hex}_{5} \mathrm{Ac}+\mathrm{Na}\right]^{+}(\mathrm{m} / \mathrm{z}$ 893), that confirms the presence of ions at $m / z 731, \mathrm{~m} / z 569$ and $m / z$ 407 due the loss of one, two and three $162 \mathrm{Da}$ (Hex res), respectively. The ion $m / z 347$ was formed by the combined loss of a Hex unit (180 Da) and of one AcHex (222 Da).

The ESI-MS/MS spectrum of $\left[\mathrm{Hex}_{6} \mathrm{Ac}+\mathrm{Na}\right]^{+}(\mathrm{m} / z$ 1055) (Fig. 4b), shows the presence of ions $m / z 893, \mathrm{~m} / z$ 731, $\mathrm{m} / \mathrm{z} 569$ and $\mathrm{m} / \mathrm{z} 407$ 
(a)

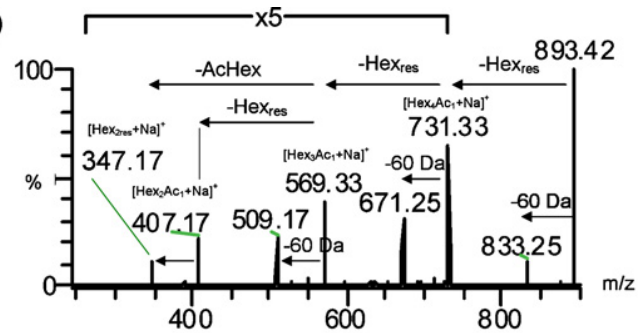

(b)

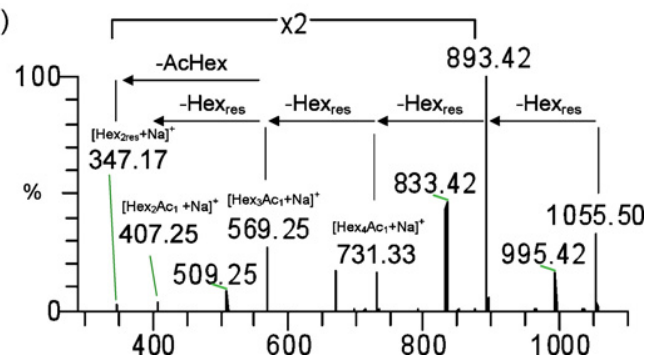

Fig. 4. ESI-MS/MS spectra of $[\mathrm{M}+\mathrm{Na}]^{+}$adducts and schematic fragmentation pathways of $\operatorname{Hex}_{5} \mathrm{Ac}_{1}$ (a) and $\mathrm{Hex}_{6} \mathrm{Ac}_{1}$ (b) for fractions $\mathrm{F}_{22}$ of $G$. triacanthos.

due the loss of one, two, three and four $162 \mathrm{Da}\left(\mathrm{Hex}_{\mathrm{res}}\right)$, respectively. The ion $\mathrm{m} / \mathrm{z} 347$ corresponds to the loss of AcHex (222 Da) plus loss of three hexose residues. These results indicate that mannans isolated from galactomannan of GT contain hexose residues bearing one acetyl group.

\subsubsection{C. pulcherrima and A. pavonina}

The ESI-MS/MS spectrum of $\left[\mathrm{Hex}_{2}+\mathrm{Na}\right]^{+}(\mathrm{m} / \mathrm{z}$ 365) and $\left[\mathrm{Hex}_{3}+\mathrm{Na}\right]^{+}(m / z 527)$ (data not shown), showed the presence of predominant ions attributed to $C / Y$-type glycosidic bond cleavage.

The ESI-MS/MS spectrum of $\left[\mathrm{Hex}_{3}+\mathrm{Na}\right]^{+}$and $\left[\mathrm{Hex}_{4}+\mathrm{Na}\right]^{+}$of AP samples (data not shown), corresponds to tri- and tetrasaccharide $[\mathrm{M}+\mathrm{Na}]^{+}$ions, respectively. ESI-MS/MS spectra of the ions at $\mathrm{m} / \mathrm{z}$ 527 and $m / z 689$ show loss of one and two Hex res respectively, confirming that they are oligosaccharides composed by hexose residues. The loss of $60 \mathrm{Da}$, with higher abundance, in the ESI$\mathrm{MS} / \mathrm{MS}$ spectrum of $\left[\mathrm{Hex}_{3}+\mathrm{Na}\right]^{+}$is a characteristic of the MS/MS spectrum of (1-4)-linked hexoses. Also the ESI-MS/MS spectrum of $\left[\mathrm{Hex}_{4}+\mathrm{Na}\right]^{+}$, presents losses of $60 \mathrm{Da}$, characteristic of the MS/MS spectra of (1-4)-linked hexoses.

The analyses of lower molecular weight fractions $\left(F_{1}\right)$ of the three galactomannans show similar structures, although some differences such as the presence of acetyl and pentosyl groups in GT galactomannan can be noticed.

\subsection{Thermogravimetric analyses (TGA) and differential scanning calorimetry (DSC)}

DSC and TGA analyses were performed in order to understand the thermal behaviour of galactomannan and how can it be influenced by polysaccharide structure. DSC was used for studying

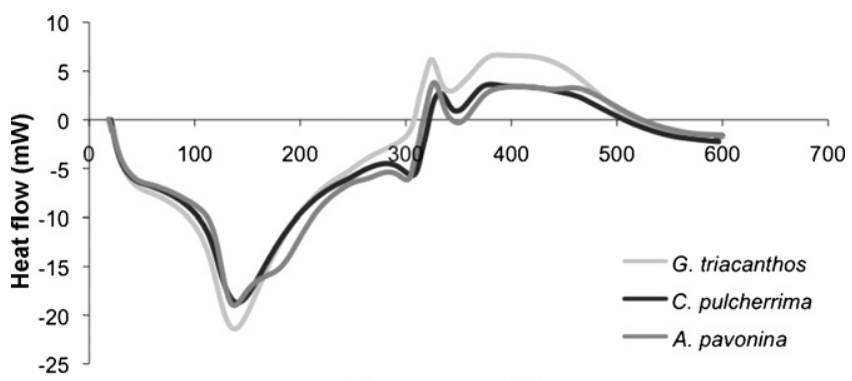

Temperature $\left({ }^{\circ} \mathrm{C}\right)$

Fig. 5. DSC scans of the three analyzed galactomannans obtained at a heating rate

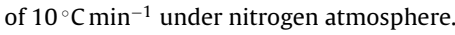

thermal transitions occurring in the course of heating under an inert atmosphere. DSC thermograms present typical natural polysaccharides DSC plots (Chaires-Martínez et al., 2008; Vendruscolo et al., 2009; Zohuriaan \& Shokrolahi, 2004). Peak temperatures for the various thermal effects as well as the associated enthalpy changes for all the polysaccharides studied are given in Table 3. Most of the DSC traces exhibited early endothermic events in the temperature range between 99 and $224^{\circ} \mathrm{C}$, which can be explained by water evaporation. Similar results were observed in other galactomannans: Vendruscolo et al. (2009) reported an endothermic event near $100^{\circ} \mathrm{C}$ and Chaires-Martínez et al. (2008) detected peaks between 117.64 and $119.71{ }^{\circ} \mathrm{C}$. The second event was related to an endothermic peak between 306.59 and $345.56{ }^{\circ} \mathrm{C}$ (Table 3).

Some differences can be observed between samples in the DSC thermograms (Fig. 5). The enthalpy change for the first thermal transition $\left(\Delta H_{1}\right)$ increased by $8.7 \%$ from AP to GT, being the GT sample the polysaccharide with the highest $\Delta H_{1}$ value. These increases have a direct relationship with the values of intrinsic viscosity and of the mannose:galactose ratio of the samples, in agreement with mannose molar content of GT, CP and AP samples of 66.9, 69.1 and $52.8 \mathrm{~mol} \%$, respectively (Cerqueira, Pinheiro et al., 2009). Na and Lee (1997) showed that the energy required for the thermal transition of lactan gum was related to the steady shear viscosity ranking of gum samples. The increase of mannose content in the sample indicates a lower branching and a higher binding energy between the backbone monosaccharides (Na \& Lee, 1997); similar results were reported by Chaires-Martínez, Salazar-Montoya, \& Ramos-Ramírez (2008) who compared guar gum with a lower content of Man/Gal ratio with locust bean gum, having guar gum displayed lower values of $\Delta H_{1}$.

Table 3 shows the values of enthalpy change for the second thermal transition, $\Delta H_{2}$. The values obtained for galactomannans of GT, $\mathrm{CP}$ and AP were $33.98,34.79$ and $47.75 \mathrm{Jg}^{-1}$, respectively. These values are related to the samples' thermal decomposition and are in agreement with the viscosity-based average molecular weight $(M v)$ and with the degrees of polymerization and branching of the samples (Riande et al., 2000, Sperling, 2006), which are both higher for AP galactomannan (Cerqueira, Pinheiro et al., 2009).

Glass transition temperature $\left(T_{g}\right)$ is a parameter associated with the system's mobility, and is defined as a physical change from a

Table 3

Peak temperatures $\left(T_{1}\right.$ and $\left.T_{2}\right)$ in DSC thermograms, enthalpy changes $\left(\Delta H_{1}\right.$ and $\left.\Delta H_{2}\right)$ and glass transition temperatures ( $\left.T_{g}\right)$ of galactomannan samples.

\begin{tabular}{|c|c|c|c|c|c|c|c|c|}
\hline Sample & Peak no. & Onset $\left({ }^{\circ} \mathrm{C}\right)$ & $T_{1}\left({ }^{\circ} \mathrm{C}\right)$ & $T_{2}\left({ }^{\circ} \mathrm{C}\right)$ & Endset $\left({ }^{\circ} \mathrm{C}\right)$ & $\Delta H_{1}\left(\mathrm{Jg}^{-1}\right)$ & $\Delta H_{2}\left(\mathrm{Jg}^{-1}\right)$ & $T_{g}{ }^{a}\left({ }^{\circ} \mathrm{C}\right)$ \\
\hline \multirow[t]{2}{*}{ G. triacanthos } & 1 & 102.05 & 137.11 & - & 205.72 & 324 & - & 56.4 \\
\hline & 2 & 311.09 & - & 322.41 & 337.13 & & 33.98 & \\
\hline \multirow[t]{2}{*}{ C. pulcherrima } & 1 & 101.52 & 139.18 & - & 203.56 & 326 & & 66.9 \\
\hline & 2 & 313.65 & - & 329.83 & 344.30 & - & 34.79 & \\
\hline \multirow[t]{2}{*}{ A. pavonina } & 1 & 112.80 & 151.36 & - & 208.13 & 298 & & 52.6 \\
\hline & 2 & 306.59 & - & 328.16 & 345.56 & - & 47.75 & \\
\hline
\end{tabular}

a Obtained by the second heating run. 


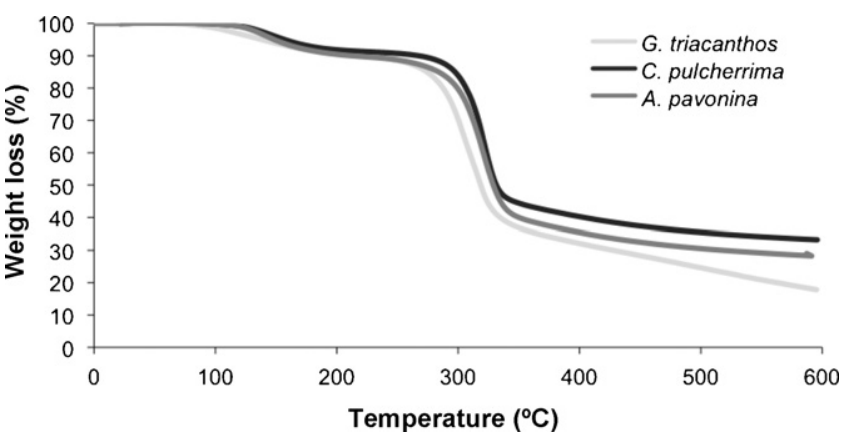

Fig. 6. Thermogravimetric curves for the three analyzed galactomannans obtained at a heating rate of $10^{\circ} \mathrm{C} \mathrm{min}^{-1}$ under nitrogen atmosphere.

glassy to a rubbery state in amorphous materials promoted by heat or addition of a plasticizer (Roos \& Karel, 1991). $T_{g}$ values of polymers can be explained by a great number of reasons as molecular weight, crystallinity and intermolecular bonding (Sperling, 2006). Chaires-Martínez et al. (2008) attribute the differences in $T_{g}$ values of galactomannans to the $\mathrm{M} / \mathrm{G}$ ratio and to the distribution of galactose units in mannose chains. Table 3 shows $T_{g}$ values for the galactomannans under consideration; these values show that a higher $\mathrm{M} / \mathrm{G}$ ratio leads to higher values of $T_{g}$. These values are close to those reported in the literature for other galactomannan sources (Chaires-Martínez et al., 2008; Yi \& Zhang, 2007).

Also TGA curves (Fig. 6) are in agreement with other works on galactomannans (Varma, Kokane, Pathak, \& Pradhan, 1997; Vendruscolo et al., 2009; Zohuriaan \& Shokrolahi, 2004), showing two mass loss events for all polymers. The first occurs near $100^{\circ} \mathrm{C}$ and may be attributed to the loss of adsorbed and structural water, which in turn is associated to the hydrophilic nature of the functional groups of each polysaccharide. The second mass loss event resulted in a weight loss of ca. $45 \%$, due to polysaccharide thermal decomposition, presenting peaks of the derivate of the weight loss curve (DTG) at $309.81,321.73$ and $320.62{ }^{\circ} \mathrm{C}$ for $\mathrm{GT}, \mathrm{CP}$ and AP, respectively (Table 4). These values are in conformity with the values presented by Vendruscolo et al. (2009) for the galactomannan of Mimosa scabrella, with values ranging between 299.7 and $311.9^{\circ} \mathrm{C}$, depending on the drying temperature. Also Varma et al. (1997) presented a $D T G$ value of $306^{\circ} \mathrm{C}$ for guar gum.

\subsection{Fourier transform infrared (FTIR) spectroscopy}

Fig. 7 shows the FTIR spectrum of the analyzed galactomannans. The IR spectra of galactomannans show peaks at 815 and $872 \mathrm{~cm}^{-1}$ that are related with the presence of anomeric configurations ( $\alpha$ and $\beta$ conformers) and glycosidic linkages, attributed to $\alpha$-D-galactopyranose units and $\beta$-D-mannopyranose units, respectively (Figueiró, Góes, Moreira, \& Sombra, 2004; Prado, Kim, Özen, \& Mauer, 2005; Yuen, Choi, Phillips, \& Ma, 2009). The broad band between 1198 and $983 \mathrm{~cm}^{-1}$ results from the stretching vibration of $\mathrm{C}-\mathrm{O}$ in $\mathrm{C}-\mathrm{O}-\mathrm{H}$ bonds (e.g. glycosidic bonds) and is related with the galactomannans' sugar composition. The peak

Table 4

Thermogravimetric data for G. triacanthos (GT), C. pulcherrima (CP) and A. pavonina (AP) galactomannan samples.

\begin{tabular}{lll}
\hline Sample & Peak & DTG $\left({ }^{\circ} \mathrm{C}\right)$ \\
\hline GT & 1 & 136.89 \\
& 2 & 309.81 \\
CP & 1 & 143.32 \\
& 2 & 321.73 \\
AP & 1 & 141.85 \\
& 2 & 320.62 \\
\hline
\end{tabular}

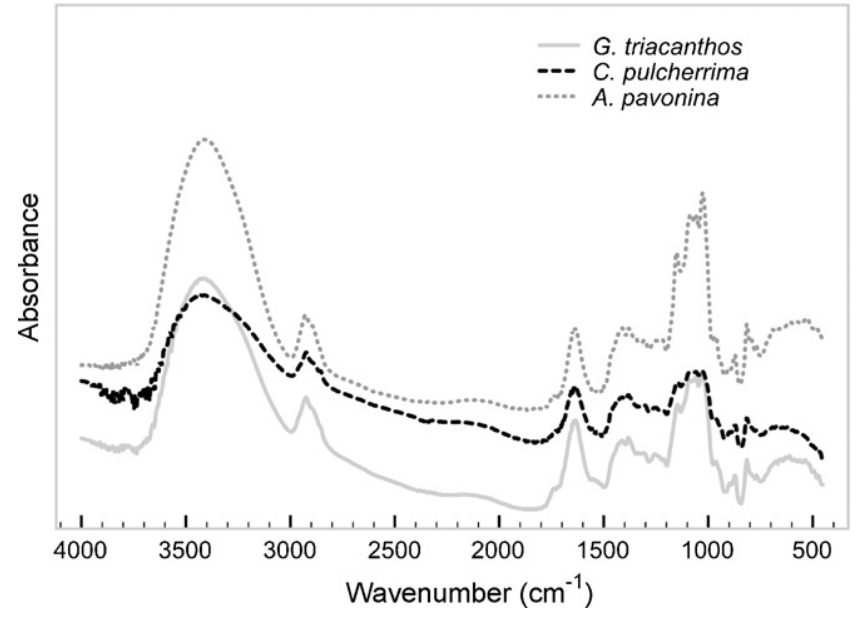

Fig. 7. FTIR spectra of the three analyzed galactomannans in the spectral region between 400 and $4000 \mathrm{~cm}^{-1}$.

at $1152 \mathrm{~cm}^{-1}$ corresponds to bending vibrational modes of $\mathrm{C}-\mathrm{O}$, present in the pyranose ring, while the broad band between 1134 and $983 \mathrm{~cm}^{-1}$ is a characteristic contribution of $\mathrm{C}-\mathrm{OH}$ bending (Figueiró et al., 2004; Prashanth et al., 2006). The broad bands ranging between $2800-3000$ and $3100-3500 \mathrm{~cm}^{-1}$ are attributed to $\mathrm{C}-\mathrm{H}$ stretching and to $\mathrm{O}-\mathrm{H}$ stretching vibration, respectively (Yuen, Choi et al. 2009).

\section{Conclusions}

The structural and thermal properties of three galactomannans from non-traditional sources (seeds of $G$. triacanthos, C. pulcherrima and $A$. pavonina) were evaluated. These three galactomannans are characterized by a 1-4-linked mannose polymer with galactose side chains attached at the C6 position. Enzymatic hydrolysis with endo- $\beta$-mannanase followed by analyses by ESI-MS/MS indicates the presence of acetyl and pentose groups in the galactomannan of $G$. triacanthos. Thermal analyses have shown that the different galactomannan compositions, with different mannose content and different molecular weight, influence their thermal behaviour. A higher content of mannose leads to higher values of enthalpy change and $T_{g}$, and the enthalpy change for the second thermal transition is influenced by the viscosity average molecular weight of the samples.

\section{Acknowledgments}

M.A. Cerqueira was recipient of a fellowship from the Fundação para a Ciência e Tecnologia (FCT, Portugal) through grant SFRH/BD/23897/2005; and B.W.S. Souza was recipient of a fellowship from the Coordenação de Aperfeiçoamento de Pessoal de Nível Superior (CAPES, Brazil).

\section{References}

Azero, E. G., \& Andrade, C. T. (2002). Testing procedures for galactomannan purification. Polymer Testing, 21, 551-556.

Baveja, S. K., Ranga Rao, K. V., Arora, J., Mathur, N. K., \& Vinayah, V. K. (1991). Chemical investigations of some galactomannan gums as matrix tablets for sustained drug delivery. Indian Journal of Chemistry, 30, 133-137.

Cerqueira, M. A., Lima, A. M., Souza, B. W. S., Teixeira, J. A., Moreira, R. A., \& Vicente, A. A. (2009). Functional polysaccharides as edible coatings for cheese. Journal of Agricultural and Food Chemistry, 57(4), 1456-1462.

Cerqueira, M. A., Pinheiro, A. C., Souza, B. W. S., Lima, A. M. P., Riberio, C., Miranda C., Teixeira, J. A., Moreira, R. A., Coimbra, M. A., Gonçalves, M. P., \& Vicente, A. A. (2009). Extraction, purification and characterization of galactomannans from non-traditional sources. Carbohydrate Polymers, 75(3), 408-414. 
Chaires-Martínez, L., Salazar-Montoya, J. A., \& Ramos-Ramírez, E. G. (2008). Physicochemical and functional characterization of the galactomannan obtained from mesquite seeds (Prosopis pallida). European Food Research and Technology, 227, 1669-1676.

Chu, C. (2003). Biodegradable polymeric biomaterials: An updated overview. In J. B. Park, \& J. D. Bronzino (Eds.), Biomaterials principles and applications (pp. 95-116). CRC Press.

Ciucanu, I., \& Kerek, F. (1984). A simple and rapid method for the permethylation of carbohydrates. Carbohydrate Research, 131, 209-217.

Coimbra, M. A., Delgadillo, I., Waldron, K. W., \& Selvendran, R. R. (1996). Isolation and analysis of cell wall polymers from olive pulp. In H. F. Linskens, \& J. F. Jackson (Eds.), Modern methods of plant analysis (pp. 19-44). Springer-Verlag: BerlinHeidelberg. Plant Cell Wall Analysis.

Daas, P. J., Schols, H. A., \& Jongh, H. J. (2000). On the galactosyl distribution of commercial galactomannans. Carbohydrate Research, 329, 609-619.

Dong, Y., Ruan, Y., Wang, H., Zhao, Y., \& Bi, D. (2004). Studies on glass transition temperature of chitosan with four techniques. Journal of Applied Polymer Science, 93, 1553-1558.

Dubois, M., Gilles, K. A., Hamilton, J. K., Rebers, P. A., \& Smith, F. (1956). Colorimetric method for determination of sugars and related substances. Analytical Chemistry, 28(3), 350-356.

Figueiró, S. D., Góes, J. C., Moreira, R. A., \& Sombra, A. S. B. (2004). On the physicochemical and dielectric properties of glutaraldehyde crosslinked galactomannan - collagen films. Carbohydrate Polymers, 56, 313-320.

Hofmeister, G., Zhou, Z., \& Leary, J. A. (1991). Linkage position determination in lithiated disaccharides: Tandem mass spectrometry and semiempirical calculations. Journal of the American Chemical Society, 113, 5964-5970.

Isogai, A., Ishizu, A., \& Nakano, J. (1985). A new facile methylation method for cellwall polysaccharides. Carbohydrate Research, 138, 99-108.

Izydorczyk, M. (2005). Understanding the chemistry of food carbohydrates. In S. W. Cui (Ed.), Food carbohydrates, chemistry, physical properties and applications. Taylor \& Francis Group.

Joshi, H., \& Kapoor, V. P. (2003). Cassia grandis Linn. f. seed galactomannan: Structural and crystallographical studies. Carbohydrate Research, 338, 1907-1912.

Krishnaiah, Y. S. R., Karthikeyan, R. S., Gouri Sankar, V., \& Satyanarayana, V. (2002). Three layer guar gum matrix tablet formulations for oral controlled delivery of highly soluble trimetazidine dihydrochloride. Journal of Controlled Release, 81, 45-56.

Manzi, A. E., Ancibor, E., \& Cerezo, A. S. (1990). Cell-wall carbohydrates of the endosperm of the seed of Gleditsia Triacanthos. Plant Physiology, 92, 931-938.

Mitsuiki, M., Yamamoto, Y., Mizuno, A., \& Matoki, M. (1998). Glass transition properties as a function of water content for low-moisture galactans. Journal of Agricultural and Food Chemistry, 46, 3528-3534

Na, K., \& Lee, K.-Y. (1997). Characteristics of the lactan gum produced from various carbon sources by Rahnella aquatilis. Biotechnology Letters, 19(12), 1193-1195.

Navarro, D. A., Cerezo, A. S., \& Stortz, C. A. (2002). NMR spectroscopy and chemical studies of an arabinan-rich system from the endosperm of the seed of Gleditsia triacanthos. Carbohydrate Research, 337, 255-263.
Neukom, H. (1989). Galactomannans: Properties and applications London: Lebensmmitel Wissenschaft und Technologie., pp. 41-45.

Nunes, F. M., \& Coimbra, M. A. (2001). Chemical characterization of the high molecular weight material extracted with hot water from green and roasted Arabica coffee. Journal of Agricultural and Food Chemistry, 49, 1773-1782.

Nunes, F. M., Domingues, M. R., \& Coimbra, M. A. (2005). Arabinosyl and glucosyl residues as structural features of acetylated galactomannans from green and roasted coffee infusions. Carbohydrate Research, 340, 1689-1698.

Prado, B. M., Kim, S., Özen, B. F., \& Mauer, L. J. (2005). Differentiation of carbohydrate gums and mixtures using Fourier transform infrared spectroscopy and chemometrics. Journal of Agricultural and Food Chemistry, 53, 2823-2829.

Prashanth, M. R. S., Parvathy, K. S., Susheelamma, N. S., Prashanth, K. V. H., Tharanathan, R. N., Cha, A., \& Anilkumar, G. (2006). Galactomannan esters-A simple, cost-effective method of preparation and characterization. Food Hydrocolloids, 20(8), 1198-1205.

Riande, E., Díaz-Calleja, R., Prolongo, M. G., Masegosa, R. M., \& Salom, C. (2000). Structure of polymers. In E. Riande, R. Díaz-Calleja, M. G. Prolongo, R. M. Masegosa \& C Salom (Eds.), Polymer viscoelasticity: Stress and strain in practice. New York: Marcel Dekker, Inc.

Roos, Y., \& Karel, M. (1991). Plasticizing effect of water of thermal the behaviour and crystallization of amorphous food models. Journal of Food Science, 56(1), 38-43.

Rosell, C. M., Rojas, J. A., \& De Barber, C. B. (2001). Influence of hydrocolloids on dought rheology and bread quality. Food Hydrocolloids, 15(1), 75-81.

Sperling, L. H. (2006). In L. H. Sperling (Ed.), Introduction to physical polymer science. NJ: John Wiley \& Sons, Inc.

Srivastava, M., \& Kapoor, V. P. (2005). Seed galactomannans: An overview. Chemistry E Biodiversity, 2(3), 295-317.

Varma, A. J., Kokane, S. P., Pathak, G., \& Pradhan, S. D. (1997). Thermal behavior of galactomannan guar gum and its periodate oxidation products. Carbohydrate Polymers, 32, 111-114.

Varshosaz, J., Tavakoli, N., \& Eram, S. A. (2006). Use of natural gums and cellulose derivatives in production of sustained release metoprolol tablets. Drug Delivery, 13, 113-119.

Vendruscolo, C. W., Ferrero, C., Pineda, E. A. G., Silveira, J. L. M., Freitas, R. A., JiménezCastellanos, M. R., \& Bresolin, T. M. B. (2009). Physicochemical and mechanical characterization of galactomannan from Mimosa scabrella: Effect of drying method. Carbohydrate Polymers, 76(1), 86-93.

Vieira, I. G. P. V., Mendes, F. N. P., Gallão, M. I., \& de Brito, E. S. (2007). NMR study of galactomannans from the seeds of mesquite tree (Prosopis juliflora (Sw) DC). Food Chemistry, 101, 70-73.

Yi, J.-Z., \& Zhang, L.-M. (2007). Biodegradable blend films based on two polysaccharide derivates and their use as Ibuprofen-releasing matrices. Journal of Applied Polymer Science, 103, 3553-3559.

Yuen, S.-N., Choi, S.-M., Phillips, D. L., \& Ma, C.-Y. (2009). Raman and FTIR spectroscopy study of carboxymethylated non-starch polysaccharides. Food Chemistry, 114, 1091-1098.

Zohuriaan, M. J., \& Shokrolahi, F. (2004). Thermal studies on natural and modified gums. Polymer Testing, 23, 575-579. 